\title{
Guadalupe Lucero
}

\section{SARACENO Y LA ARAÑA: LA FIGURACIÓN POSTHUMANA, ENTRE REAPROPIACIONES Y DERIVAS NO ANTRÓPICAS}

En este trabajo nos proponemos realizar una lectura crítica de la obra reciente del artista argentino Tomás Saraceno, desde la perspectiva del materialismo posthumano. Esta perspectiva conjuga dos líneas de investigación con gran impacto en los debates filosóficos contemporáneos, a saber el posthumanisno y el resurgimiento de diversas corrientes que se reconocen como materialistas. El posthumanismo se ha constituido en la última década como un espacio de profusa producción en el campo de las humanidades. El descentramiento de lo humano implica una reconsideración de su horizonte de referencia y especialmente de su función jerarquizadora respecto de lo que hay. Lo posthumano se erige como aquel campo de saber que podría reconfigurar los principios fundamentales de nuestra relación con otros agentes humanos o no. ${ }^{1}$ Desde el punto de vista ontológico, una estética materialista y posthumana reclama un tratamiento que no solo desplace al hombre como centro de la experiencia estética y de la experiencia en general, sino también que afirme una desjerarquización de lo existente. Su particular alianza con el pensamiento feminista y los estudios animales ha trazado un horizonte nuevo para una discusión que parecía ya agotada luego de la larga convalecencia de los modernos conceptos de sujeto y hombre durante el siglo xx. En cierto modo, lo que los estudios enmarcados en las posthumanidades problematizan no es ya el concepto de hombre y sujeto en sí mismos, sino su estructura hermenéutica y problemática que parece proyectarse sobre los conceptos que vendrían en su relevo, especialmente el concepto de vida. Por otro lado, la rehabilitación de un debate materialista llevado adelante no solo por las líneas de investigación vinculadas a las posthumanidades, sino también por los efectos de la crítica al correlacionismo por parte del realismo especulativo, ${ }^{2}$ la ontología orientada a obje$\operatorname{tos}^{3}$ y la necesidad de volver a pensar la materia más allá de sus capturas
M ATÈRIA, núm. 18-19, 2021 ISSN 1579-2641, p. 203-218

Recepció: 19-03-2020

Acceptació: 26-2-2021

${ }^{1}$ Cfr. Rosi Braidotti, Lo posthumano, trad. Juan Carlos Gentile Vitale, Barcelona, Gedisa, 2015 (Cambridge, 2013), p. 16. Braidotti recorre en este estudio fundamental la posibilidad de delinear una nueva subjetividad posthumana a partir de la crítica del antropocentrismo tanto desde los estudios feministas como antiespecistas. Desde la perspectiva latinoamericana que aquí querríamos sostener, lo posthumano permitiría a su vez releer la tradición decolonial anudando la crítica al antropocentrismo con la crítica más general a las lógicas de producción colonial, especialmente el extractivismo.

${ }^{2}$ Cfr. Quentin Meillassoux, Después de la finitud. Ensayo sobre la necesidad de la contingencia, trad. Margarita Martínez, Buenos Aires, Caja Negra, 2015 (París, 2006). Esta obra central de la corriente filosófica conocida como realismo especulativo señala en su tesis 
más relevante que es necesario discutir la premisa que desde Kant podemos reconocer como correlacionismo, es decir, que los fenómenos del mundo son relevantes para el conocimiento en función de su relación con el sujeto humano.

${ }^{3}$ Cfr. Graham Harman, Object-Oriented Ontology: A New Theory of Everything, Londres, Penguin Random House, 2017. La ontología orientada a objetos continúa la crítica del realismo especulativo al correlacionismo haciendo especial hincapié en los modos de existencia de las cosas más allá de las relaciones humanas en las que pueden verse involucradas. Desde este punto de vista, los existentes inanimados establecen relaciones entre sí y su análisis excede los modos en los que los vivientes o los humanos se los apropian bajo el modo de lo que es para otro.

${ }^{4}$ Cfr. Karen BARAd, Meeting the Universe Halfway. Quantum Physics and the Entanglement of Matter and Meaning, Duke University Press, 2007. Nos interesa especialmente el punto de vista de Barad respecto de los discursos culturalistas en torno a la materia. Barad recusa las perspectivas que consideran que es posible reducir el problema de lo existente a una lucha que se despliega fundamentalmente en los discursos para luego tener efectos en los cuerpos.

5 Max Horkheimer y Theodor W. Adorno, Dialéctica de la Ilustración, trad. Juan José Sánchez, Madrid, Trotta, 2006 (Nueva York, 1944), esp. «Concepto de Ilustración», p. 59-95.

${ }^{6}$ Georg W. F. HEgEL, Lecciones sobre la estética, trad. Al- culturales, ${ }^{4}$ ha puesto nuevamente el foco en el modo de ser de lo no-humano, resdistribuyendo la potencia de actual sobre todo lo existente.

En este trabajo buscamos pensar el impacto que esta perspectiva puede tener en el ámbito del arte y de la producción imaginaria, al mismo tiempo que señalar cómo ciertas derivas aparentemente posantrópicas reproducen la lógica de extracción material y simbólica características del capitalismo colonial y neocolonial bajo la forma del así llamado extractivismo. De este modo, querríamos señalar la necesidad de que la crítica a los modos de vida capitalista profundice el análisis sobre las formas de apropiación de lo existente que siguen encontrando en lo humano el destino y sentido para todo lo que hay. Como ya señalaran Adorno y Horkheimer en la Dialéctica de la Ilustración ${ }^{5}$ consideramos que la lógica del dominio que caracteriza a la modernidad, y que se aplica en primer lugar sobre lo no-humano para luego extenderse sobre lo humano, es la matriz que solo puede desarmarse poniendo en cuestión la noción misma de finalidad humana. Ya que, incluso en lo que se presenta como utopía artística de un nuevo ser en común más que humano, crece lo que nos hunde.

\section{La utopía arácnida}

En el campo de las artes, el siglo xx parece haber recorrido el camino augurado por Hegel cuyo despliegue implicaba su progresiva desmaterialización. ${ }^{6}$ Desde el punto de vista de las prácticas artísticas nacidas de la segunda posguerra, tal desmaterialización implicó un corrimiento desde los materiales artísticos tradicionales -íntimamente vinculados con una especificación y separación de los lenguajes y las gramáticas de los sentidoshacia una lógica performática de la obra artística que encontrará en el situacionismo, los diversos conceptualismos, el minimalismo, entre otros, una amplia diversidad de declinaciones que tienen quizás algo en común: la inclusión del espectador en la obra de un modo diferente de aquel que señalaba Foucault ${ }^{7}$ en Las meninas de Velázquez. En el análisis foucaultiano del pintor español, el espectador se constituye como el punto externo ideal hacia el cual la obra se dirige y que a la vez permite estabilizarla. En la obra desmaterializada el espectador entra en la escena literalmente: participa y se involucra a través de una dimensión que los más optimistas han pensado utópicamente como nuevas formas de construcción comunitaria.

Sin embargo, el arte de posguerra tuvo que vérselas -explícita o implícitamente- con la fulminante sentencia adorniana respecto de la posibilidad de continuar produciendo cultura después de Auschwitz. Ya que el presupuesto comunitario que la cultura implicaba se encontraba para siempre 
cosificado. ${ }^{8}$ Vemos hasta qué punto es necesario considerar en conjunto la desmaterialización y disolución de los lenguajes purificados por algunos de los relatos de las vanguardias, con la pérdida de horizonte libertario para la cultura. El botín de los bienes culturales se revela como botín de los vencedores, y por lo tanto como barbarie. Este es el horizonte común que quizás permita vincular esa serie de movimientos diversos ${ }^{9}$ que comienza a preguntarse por la pertinencia objetual de la obra para volcarse hacia una lógica de situación, escena, performance o acción, rompiendo con la presencia material de la obra tal como había sido considerada hasta entonces.

La crítica de la cultura como horizonte histórico de la así llamada humanidad, ha encontrado, después de Adorno, otros detractores. En un pequeño texto titulado «Cultura, ¿un concepto reaccionario?», Guattari se ocupa de responder la pregunta por la positiva e indicar cómo el concepto tiene un sentido ante todo jerarquizador y de corte colonizador. ${ }^{10}$ Proveniente del debate epistemológico, Bruno Latour ha retomado el binomio naturaleza-cultura en Cara a cara con el planeta para mostrar cómo la cultura no es un concepto separado sino que se determina en el mismo movimiento en el que se construye el concepto de naturaleza como su opuesto. Naturaleza y cultura solo tienen sentido una en relación con la otra, porque son en realidad un solo concepto con dos caras. ${ }^{11}$

¿Cómo pensar entonces el arte más allá de los materiales expresivos históricos y a la vez más allá del horizonte simbólico de la cultura? ¿Qué queda del arte si lo que parece ya no ser pertinente es la excepcionalidad del hacer humano como cantera de sentido? ¿Cómo distinguir el arte de la naturaleza, para utilizar la vieja dicotomía kantiana, donde ya no tiene sentido la separación entre naturaleza y cultura? ¿Qué lugar queda entonces para la obra, como especial efecto del hacer humano?

El arte del siglo xxi ha reformulado a su modo esta cuestión. El material parece retornar aquí y allá como elemento central del quehacer artístico, como si resultara ya más simple abandonar el privilegio de lo humano y abrazar sin más la inculta agencia inhumana, donde la obra parece un concepto si no pasado de moda, al menos inactual. Quizás un ejemplo nos permita comprender el alcance y especialmente los límites de este aparente triunfo de lo inhumano en el arte contemporáneo. Para ello nos detendremos en la problematicidad del concepto de obra, y especialmente en su relación con el horizonte comunitario, en el ejemplo de las obras de Saraceno montadas en el Museo de Arte Moderno de Buenos Aires durante 2017 en el marco del proyecto «Cómo atrapar el universo en una tela de araña» y la exhibición «On air» montada en el Palais de Tokyo, París, en 2018. Este punto de partida nos permitirá recorrer una serie de cuestiones que consideramos fundamentales para la delimitación de los problemas estéticos que fredo Brotons Muñoz, Madrid, Akal, 2007 (Berlín, 1842), p. 64-67.

7 Cfr. Michel Foucault, Las palabras y las cosas. Una arqueología de las ciencias humanas, trad. Elsa Cecilia Frost, Buenos Aires, Siglo XxI, 2002 (París, 1966), p. 13-24.

8 Cfr. Theodor W. Adorno, Dialéctica negativa, trad. José María Ripalda, Madrid, Taurus, 1984 (Frankfurt, 1966), p. 365.

9 Queremos incluir aquí a toda una serie de emergentes que se suceden en la década del sesenta, que van desde el situacionismo francés, a los conceptualismos latinoamericanos, el minimalismo norteamericano y el pop. Cada uno de estos movimientos surge en circunstancias muy concretas y específicas, y sin embargo tienen en común el haber operado un giro que desmaterializa la histórica lógica de los materiales artísticos. Para un recorrido en torno a las similitudes y diferencias entre estos movimientos ver Guadalupe LUCERO, "Neovanguardia, situacionismo y otros fantasmas», Paula FLEISNER y Guadalupe LUCERO (comp.), El situacionismo y sus derivas actuales: acerca de las relaciones entre arte $y$ política en la estética contemporánea, Buenos Aires, Prometeo, 2014, p. 19-32.

${ }^{10}$ Félix GuATtARI, "Cultura, ¿un concepto reaccionario?» en F. Guattari, \& S. Rolnik, Micropolíticas. Cartografías del deseo, trad. Florencia Gómez, Madrid, Traficantes de sueños, 2006 (Petrópolis, 2005), p. 27-36.

${ }^{11}$ Cfr. Bruno Latour, Cara a cara con el planeta. Una nueva mirada sobre el cambio climático alejada de las posiciones apocalípticas, trad. 
Ariel Dilon, Buenos Aires, Siglo xxI, 2017 (París, 2015), esp. "Sobre la inestabilidad de la (noción de) naturaleza», p. 21-56.

12 Me refiero al debate que llevaron adelante, con una serie de intervenciones que de uno $u$ otro modo se referían entre sí, Blanchot, Nancy, Agamben, Derrida, Rancière, desde finales de los 80 y durante los 90 del siglo pasado, y cuyo texto central es quizás La comunidad desobrada de Jean-Luc Nancy. (Nancy, 2001).

13 Jussi PARIKKA, «A Recursive Web of Models: Studio Tomás Saraceno's Working Objects», Configurations, 28: 3 (summer 2020), p. 309-332. D0I: https://doi.org/10.1353/ con.2020.0019 reclaman un tratamiento materialista y posthumano. La noción de obra y su profusa crítica serán retomadas aquí a partir de la variante que introduce el uso de las arañas como agentes artísticos y la particular factura imaginaria que efectúan. ¿Qué tipo de extraña comunidad es esta que se da entre artrópodos, artistas, curadores y científicos? ¿Qué obra monstruosa surge de allí? ¿Puede una factura imaginaria no humana, más que humana, como repite el artista, destituir la obra?

El ya viejo debate en torno a la comunidad, ${ }^{12}$ abierto sobre el horizonte de la preocupación comunitaria europea y la rehabilitación de ese concepto sospechado de nazismo, se concentraba en el concepto de obra. Para JeanLuc Nancy, la comunidad solo puede volver si abandona su carácter obrante, operativo, comunional en tanto que unitario. La comunidad sería entonces la de un modo de ser-con, ser-juntos, desobrado, retirado de cualquier productividad que permitiera ver en los productos la reafirmación identitaria del agente. La obra común quedará conjugada como obra de muerte, productividad de la apropiación masiva de los cuerpos, de su uso y desecho en pos de la obra comunitaria. Desde este punto de vista, el arte ha hecho suyo a su modo este no-programa, retirando la acción del artista y dejando en su lugar la apertura a un acontecer que ya no tendría en la subjetividad talentosa su centro, sino en las redes y conexiones que una nueva obra con forma de dispositivo facilitaría. ¿Pero no serán estas redes nuevamente la telaraña que teje pacientemente el antropismo?

Desde una perspectiva interesada en los modelos estructurales de la obra de Saraceno, Jussi Parikka ${ }^{13}$ ha encontrado en ella las formas de una suerte de epistemología por venir. A partir de la imbricación que la obra de Saraceno propone entre ciencias biológicas, arquitectura, modelos informáticos, diseño e intervención artística, se presenta como un modelo privilegiado para pensar emergentes conceptuales relevantes para los marcos teóricos de las humanidades ambientales. Las arañas permiten pensar la agencia no-humana en colaboración con la humana, como working objects (objetos que trabajan) que generan esculturas materiales más allá de toda prerrogativa humana para el arte. Estas esculturas complejizan y a la vez habilitan nuevas lógicas de conexión, registro e inscripción para el viejo concepto de red, a menudo demasiado trillado y evidente. De acuerdo con la precisa lectura de Parikka, la revisión del concepto de red es una de las cuestiones centrales que este particular agenciamiento artístico-científico pone en juego. Si desde mediados de los años 90, y como consecuencia del advenimiento de Internet como red mundial, el concepto de red se convirtió en la metáfora cliché para pensar una nueva cultura en adelante global, la obra de Saraceno tiene la virtud de figurarla materialmente,y por lo tanto problematizar su esquema imaginario. Esta experimentación material con 
las redes habilita nuevos modelos para las teorías y discursos que se anudan en torno a este concepto a menudo utilizado como una referencia transparente a lógicas de interconexión relacional. El trabajo realizado en el Estudio Saraceno implica el mantenimiento de una gran colección de más de 300 arañas que tejen sus redes en los cubículos provistos para ese fin. Se trata a su vez del análisis, mapeo y reconstrucción digital de las redes, lo que permite una producción inestimable de información a propósito de sus estructuras, sus propiedades arquitectónicas y sus lógicas internas de creación y transformación. Asimismo, el Estudio Saraceno lleva años de experimentación con redes híbridas, es decir, tejidas por diversas especies puestas artificialmente en común para realizar trabajos en colaboración ${ }^{14}$ La tela de araña visibiliza de modo privilegiado toda una estructura vibrante de la materia que, en tanto que puede ser medida y transmitida, nos implica de un modo sensiblemente novedoso, como si los mundos de J. von Uexküll ${ }^{15}$ nos revelaran códigos ocultos para nuestro mundo humano.

Bruno Latour también se ha interesado especialmente en la obra de Saraceno. A partir de la pregnancia del concepto de red, Latour ${ }^{16}$ se acerca a la obra del artista tucumano para ver allí las dos caras de este concepto estrella, que parece arrogarse a la vez la pérdida del hacer como motor del sentido -para distribuirlo, diseminarlo, perderlo en las múltiples conexiones- como la posibilidad de una explicación total. Contra y junto al concepto de red Latour convoca el concepto de esfera tal como es pensado por Sloterdijk. ${ }^{17}$ La red, que también podría ser pensada a través del concepto deleuziano-guattariano de rizoma, acentúa la interconexión, la posibilidad de crecer o abrir líneas en cualquier dirección, comunicación de puntos cualesquiera bajo cualquier tipo de relación. Por su parte la esfera, pliegue que hace membranas y señala la creación de una interioridad en la exterioridad absoluta, nos remite al mundo envolvente de un sujeto o una comunidad, la morada, lo propio, el horizonte como curvatura de un mundo a mi alrededor. La red y la esfera parecen señalar de modo emblemático los modos de ser del capitalismo globalizado. Por un lado una exacerbación de la idea de conexión: hipercomunicación pero también hiperexplotación capitalista que alcanza una radical capilaridad. Por otro la multiplicación de espacios cerrados, envueltos, globos o esferas, fronteras y vigilancia, cierres cada vez más complejos que crean interiores e interioridades, identidades y exclusiones. Latour se interesa por esta tensión a propósito de la obra que Saraceno montó en la Bienal de Venecia en 2009, Galaxies forming along Filaments, Like Droplets along the Strands of a Spiderweb. En ella Saraceno monta una impresionante estructura de redes con tensores elásticos. La red forma en determinados espacios-puntos grandes esferas, atravesadas y tensadas en la red, pero a la vez claramente distinguibles y cerradas.
14 Para una detallada descripción del tipo de trabajo que se realiza en el Estudio Saraceno especialmente en torno a las arañas cfr. Sasha Engelmann, "Social Spiders and Hybrid Webs at Studio Tomás Saraceno», Cultural Geographies 24:1 (Jan. 2017): p. 161-169, doi:10.1177/14744 74016647371

15 Jakob von UEXKÜLL, Mondes animaux et monde humain. Suivi de Théorie de la signification. Paris, Denoël, 1965.

16 Bruno Latour, "Some Experiments in Arts and Politics» en e-Flux Journal $n^{\circ} 23$ (Marzo de 2011), https:// www.e-flux.com/journal/23/67790/some-experiments-in-art-and-politics/ [consultado el 18 de marzo de 2020].

17 Peter Sloterdijk, Esferas I. Burbujas. Microesferología, trad. Isidro Reguera, Madrid, Siruela, 2017 (Frankfurt, 1998). 
18 De acuerdo con el concepto acuñado por Gilles Deleuze y Félix Guattari, que implica la captación de un bloque de sensación y su carácter inhumano. Gilles DELEUze y Félix GuATTARI, ¿Qué es la filosofía?, trad. Thomas Kauf, Barcelona, Anagrama, 1993 (París, 1991), p. 170.

19 Pablo Semán, "Posthumano» en Tomás Saraceno: cómo atrapar eluniverso en una telaraña (catálogo de exposición, MAMBA, 2017), Buenos Aires: Museo de Arte Moderno de Buenos Aires, 2017, p. 31.
El título dice pequeñas gotas de agua en una tela de araña. La gota de agua aparece aquí como posible imagen del globo, pequeño Aleph mentado en la idea de galaxia, que a su vez se imprime sobre la quizás vetusta idea de mundo. La galaxia parece hablar del afuera del mundo, lo supralunar, el universo como mundo de mundos, que puestos infinito sobre infinito equiparan lo infinitamente pequeño y lo infinitamente grande.

Aún sobre la base superficial de la red, es posible siempre plegar, redondear, construir una esfera, un mundo. De aquí lo propiamente humano y comunitario de la esfera, y también del pliegue. Hacer mundo es hacer volumen de un plano, agregarle una dimensión. El mundo curvado sobre el hombre, mundo humano, es necesariamente pliegue o esfera que se separa, al menos provisoriamente, de la red incorporal y anoréxica, como la llama Latour siguiendo a Sloterdijk. La esfera interior ha sido profusamente criticada en la filosofía contemporánea cuando adolece de la pérdida de relación con la red, que la tensa y a su vez la conecta con su afuera.

En una de las obras montadas en 2018 en el Palais de Tokyo de París, Saraceno complejiza aún más esta tensión entre esferas y redes introduciendo la vibración que permite comunicar las distintas partes de la estructura a través de una recodificación sonora. A diferencia de la obra de 2009, los espectadores son ahora invitados a tocar la red para que las vibraciones generadas se amplifiquen como ondas sonoras y retornen a la estructura musicalmente. Lo que era visualmente aprehensible en la obra estática, se torna experimentable dinámicamente, del mismo modo que opera la vibración en la tela de araña, comunicando los signos que la presa emite con su movimiento.

Sin embargo, entre las estructuras de redes y esferas, y las arañas propiamente dichas algo ha cambiado. Las redes venecianas, que incluían incipientes o definidas galaxias, podían pensarse como un percepto, ${ }^{18}$ que facilita la experimentación de la compleja interacción entre dos conceptos (en este caso, la red y la esfera, el rizoma y el pliegue). La instalación de las redes generadas por los arácnidos en el museo, en cambio, se abandona a la lógica del hacer del otro, bajo la aparente imagen de la red. Los mundos de las gotas desaparecen. Podríamos pensar que esa desaparición abre la posibilidad de acceder a otros mundos, ya no humanos, el mundo de la araña, es decir, el afecto de la araña. Pero ¿cómo la obra puede acaso conectar los mundos invivibles y heterogéneos de las arañas con los mundos humanos, demasiado humanos, del museo de arte moderno?

Pablo Semán ${ }^{19}$ se pregunta justamente por este nuevo mundo que incluye la relación heterogénea e interespecies, y analiza la obra de Saraceno en términos de lo posthumano. Esto posthumano se entiende bajo la lupa de un progresivo ensanchamiento de la humanidad, que terminaría por descentrar el concepto de lo humano. La maravilla ante la técnica de la natu- 
raleza podría abrir así un mundo menos antropocentrado. Pero también todo lo contrario, como sabemos desde Kant. ${ }^{20}$

El catálogo de la exposición se abre con una particular concepción de la obra:

Cuando el Museo de Arte Moderno de Buenos Aires invitó al artista tucumano Tomás Saraceno residente en Berlín, a realizar su primera gran exposición en una institución argentina, él decidió a su vez, invitar a miles de arañas a colaborar en el proyecto. Todos empezamos a actuar en sintonía, a asumir nuestro lugar en el universo; cada uno, como una pieza más del paisaje cósmico al que pertenecemos, como una red en la que los elementos se transforman los unos a los otros. Una araña que teje sus filamentos, una partícula de polvo cósmico que flota en el espacio, un ser humano que la respira, una galaxia que todo lo contiene. ${ }^{21}$

Es decir, se trata de una serie de invitaciones, que llaman a desplazarse de aquí para allá. El museo invita al artista, luego, el artista invita a las arañas a colaborar. Extraño eufemismo para nombrar el secuestro de las arañas de su medio natural y su traslado al museo para que allí, fuera de su medio, trabajen durante seis meses, y luego, finalmente, expropiarles su trabajo bajo el nombre del artista. La noción de sintonía suena al menos forzada. Quizás exageramos. ¿0 acaso nos parece viable la posibilidad de que las arañas sean consideradas sujetos de derecho y que por lo tanto pueda ponerse en cuestión su uso bajo estos términos? Seguramente esta pregunta se encuentre fuera de foco incluso en el marco de los más avanzados debates en torno del derecho animal. En cualquier caso, ¿es posible hablar de trabajo conjunto, en equipo? Quizás el título de la muestra nos dé mayores elementos para analizar el gesto.

"Cómo atrapar el universo en una telaraña»: nótese la ausencia de signos de pregunta, que convierten a la frase en afirmación: Tomás Saraceno, [nos muestra] cómo atrapar el universo en una telaraña. Para ello en primer lugar, necesitamos las arañas. Con la venia de los científicos especialistas en arañas, los artrópodos serán estudiados, manipulados y expropiados. La araña ha caído en otra tela, la del artista. Si la araña nos sirve aquí de algo, es para crear un dispositivo de captura (a fin de cuentas no otra cosa es la telaraña) que nos permita atrapar el universo, es decir, en la grandilocuencia de semejante idea, alcanzar la medida finita de lo infinito, comprenderlo o dominarlo, lo mismo da. La araña teje la tela para comer y para habitarla, doble dispositivo de morada y trampa. Atrapar el universo, hacer como la araña, sería de algún modo construirlo como morada a la vez que entramparlo para devorarlo. Pero, vemos el desliz, la araña no se
${ }^{20}$ Cfr. Immanuel KANT, Crítica de la facultad de juzgar, Primera Introducción, trad. Pablo Oyarzún, Caracas, Monte Ávila, 1992 (1790).

21 Tomás Saraceno: cómo atrapar eluniverso en una telaraña (catálogo de exposición, MAMBA, 2017) Buenos Aires: Museo de Arte Moderno de Buenos Aires, 2017, p. 9. 
22 Gilles Deleuze y Félix Guattari, Mil mesetas. Capitalismo y esquizofrenia, trad. José Vazquez Pérez, Valencia, Pre-Textos, 2002 (París, 1980), p. 321.

23 Carlos Gamerro, "Borges, la araña» en Tomás Saraceno..., ed. cit., p. 15. come ella misma la tela. El universo es la mosca. Y a su vez, la araña no teje un ardid, sino que la tela da cuenta simplemente del devenir conjunto de la araña y la mosca:

Se ha observado, con frecuencia, que la tela de araña implicaba en el código de ese animal secuencias del propio código de la mosca; diríase que la araña tiene una mosca en la cabeza, un «motivo» de mosca, un «ritornelo» de mosca. ${ }^{22}$

Los autores de Mil mesetas dicen claramente que no se trata de afirmar que la araña piensa la mosca, o la imita. Por el contrario, la araña entra en un devenir, donde la tela encaja la mosca. Así las cosas, la araña no atrapa propiamente la mosca, sino que en ese particular encaje que es la tela, encontrará su alimento disponible, podrá, una vez encajada la mosca, terminar su trabajo de tejido sobre ella. La tela, por su parte, no hace propiamente nada. Diferente es la propuesta del artista: querer capturar el código del universo para construir una tela en la que se encaje: hete aquí el principio antrópico a plena luz.

En una parte de la instalación montada en Buenos Aires en 2017, vemos una araña que es iluminada y proyectada junto con lo que se nos dice que es polvo cósmico o estelar. Podemos quizás pensar, a partir de la serie de movimientos metafóricos que motorizan la relación entre el polvo cósmico que flota - polvo atrapado a su vez por otras redes- que la tela quiere ser aquí imagen del mundo. Pensar el universo bajo el signo de la mosca en la tela, a pesar de que, como afirma Gamerro, ${ }^{23}$ en el centro esté la araña devoradora, es tranquilizante. Vieja deriva borgeana, donde el laberinto, aun aterrador, es al menos una imagen del mundo. Pero, dice Gamerro que dice Borges, del universo no podemos afirmar lo mismo, debemos confrontar allí con el puro caos, respecto del cual la tela solo puede ser un consuelo, humano demasiado humano.

En el mismo catálogo, Félix Bruzzone señala la complejidad de aquello que sin matices es mentado bajo la idea de colaboración. En el relato que nos ofrece Bruzzone, unos personajes dedicados a contar estrellas y arañas usan la capacidad de nominar como particular medida de control. Nombrar la araña que surge del fuego y parece mirarlos tranquiliza, da una medida humana al monstruo del leño. Pero luego se nos presenta otra imagen: la pesadilla de las miles de arañas surgiendo del tronco que impide toda nominación. El otro arácnido, como lo múltiple, no admite nombre, ni medida. No se nos dice en el relato, pero podemos anticiparnos, que ese otro ha venido a devorarlos. ¿Para qué si no? Como en la parábola que Brecht supo narrar de modo estupendo en $L a$ excepción y la regla, el miedo se convierte en un motivo razonable para acabar con lo que nos atemoriza. Recordemos que en la obra de Brecht, el empresario justifica el asesinato de un changarín ayudante porque tenía razones para te- 
merle, y ante el juez explica los motivos de ese temor irrefutable. Parece que nos hemos alejado totalmente del gesto de Saraceno, pero veremos que este modo particular del obrar, el arrebato de los cuerpos como gesto fundador de lo común, en tanto que nos une una complicidad compartida, un temor y unas razones convincentes, puede reencontrarse en su trabajo con las arañas.

Principio y fin último del sentido, el artista captura a su otro, para expropiar su trabajo, a través del extraño artilugio del ser en común. Se trata de asumir nuestro lugar en el universo y la idea de colaboración implica una desviación no inocente respecto de los modos de producción, sean estos productos-estructuras, modelos conceptuales o diseño de otros mundos. Asumir nuestro rol en el universo bajo la lógica de la colaboración en común, donde la jerarquía parece volatilizarse en pos de una vaga idea de lo global, y donde no tenemos ningún tipo de libertad ni decisión sobre el rol que se nos asigna, no es sino lo que solemos escuchar de parte de los paladines de un neoliberalismo cuya ideología queda al descubierto al analizar con mayor detenimiento qué lugar le toca a la araña y qué lugar al artista. ${ }^{24}$

Hubo un tiempo en que la relación con ese otro, sujeto de explotación y expropiación del trabajo, era asumida por el artista como desocupación propia y del otro, pero a cambio de una retribución en dinero. Oscar Bony expuso en «Experiencias 68» del Instituto Di Tella de Buenos Aires a una familia obrera. Se le pagaba al padre el equivalente al doble de su salario por no hacer específicamente nada. La torsión comenzaba allí, la relación social como materia del arte, expuesta y problematizada. ¿Había allí también expropiación de plusvalía, como en la fábrica? En cualquier caso, lo problemático quedaba puesto en relieve, la productividad desocupada y desobrada. La convocatoria a las arañas parece ya no querer saber nada con las problemáticas relaciones sociales y de clase, el eufemismo de la colaboración permite el uso libre de ese otro arácnido, torsión sobre la esfera del mundo humano hasta considerar que incluso se trata de una metáfora adecuada para el universo.

Entre la obra de Venecia de 2009 y la de Buenos Aires en 2017, parece haber habido un desplazamiento formidable. Lo que en una parecía tensión entre red y esfera, se torna pura red, con la esfera ausente, pero para hacer de la esfera, en tanto universo, una interioridad total.

\section{Figuraciones posthumanas}

La crítica ha sido casi unánime respecto de cómo leer en la obra de Saraceno modelos conceptuales y perceptuales. El artista argentino ha tocado la fibra exacta de nuestro tiempo, logrando aunar discursos artísticos, científicos, filosóficos, de un modo exitoso. Ha incorporando modelos naturales
24 Respecto de la objeción de maltrato animal que el propio Estudio Saraceno visualiza, Sarah Engelmann recuerda todos los cuidados que requieren las arañas, tanto respecto de las condiciones ambientales como sociales, ya sea inter o intra-especies, y que el Estudio cumple con creces. Se nos narra la relación atenta que la cuidadora de las arañas establece con los insectos y lo que se logra aprender de ellos. Consideramos sin embargo que estas aclaraciones no modifican en nada el punto extractivista de la objeción: las arañas trabajan para el artista sin reciprocidad. Cfr. Sarah EngeLMANN, art. cit., p. 4. 
como interlocutores necesarios para la generación y creación de modelos humanos en relación de difracción, como indica Parikka, antes que de representación. Ha logrado que esos mundos más que humanos entren definitivamente en la escena.

Si Saraceno nos interpela obsesivamente, es porque desencadena toda una discusión filosófica en torno a la obra que problematiza los temas que consideramos urgentes y necesarios para pensar tanto el arte como las ciencias y la política. Consideramos que es fundamental pensar la particular relación entre arte, política, ciencias (humanas, posthumanas, naturales) en el anudamiento con la emergencia climática y los diversos discursos ecocríticos. Diríamos que, por un lado, en las obras del artista tucumano encontramos el dispositivo que logra descentrar la lógica del obrar y la agencia humana para habilitar una figuración no-humana, en este caso arácnida. Este desplazamiento es exitoso porque los modos de ser no-humanos convocados abren para la filosofía, la ciencia y el arte mismo nuevos problemas solo visibilizados gracias al particular modo de existencia que es la obra. Pero ella no se cierra en un supuesto círculo virtuoso, sino que, por el contrario, hace de lo no-humano convocado un fondo cuya disponibilidad no es reversible y que por lo tanto se presenta necesariamente bajo el más viejo de los antropocentrismos: los mundos no-humanos abren nuevas canteras para la explotación humana tanto material como simbólica, sin ningún tipo de reciprocidad.

Obstinados en una perspectiva que no quiere renunciar al viejo problema nietzscheano y también marxiano del ¿quién habla? o ¿qué voluntad manda?, querríamos divergir de esta suerte de consenso positivo respecto del trabajo con lo así Ilamado no-humano. La obra de Saraceno nos permite pensar el carácter fallido de ciertas intervenciones artísticas en torno al horizonte del fin de la excepcionalidad humana. La noción de comunidad y la idea misma de colaboración y participación, encuentra en el ejemplo de las arañas su límite hermenéutico. Lejos del problema de la explotación que la obra de Bony exhibía en el museo, Saraceno se abandona a los discursos que intercambian trabajo por colaboración, nublando la lógica extractiva que pone a disposición cuerpos y recursos en pos de la obra (no importa aquí que la obra sea la del progreso, la del capital o la del artista) por una retórica de roles y funciones dentro de un supuesto sistema universo.

La figuración posthumana a la que apelamos en el título no alcanza para desjerarquizar lo humano. Una figuración posthumana como la de las arañas de Saraceno nos presenta una lógica recolonizadora que no resulta en ningún antiantropismo. Considerar una figuración posthumana que habilite modos de pensamiento y conceptualización no antrópicos, requiere de un análisis que determine las posibilidades para el arte de abandonar los 
fines humanos, o lo que es lo mismo, los fines del hombre. Si deliberadamente equiparamos ambos términos no es porque olvidemos que habría humanos que podrían reclamarse como no hombres, sino porque el sentido excluyente y jerarquizante con el que carga toda lógica humanizadora equivale -para la visión del mundo occidental y colonial- a la máquina que ordena lo existente desde el punto de vista idealizado de un hombre blanco, europeo ${ }^{25}$ y -agreguemos- burgués. En otros términos, los fines humanos serían consecuencia de un antropocentrismo que es a la vez un androcentrismo, cuyo sentido más acabado se encuentra en las sucesivas campañas colonizadoras modernas ${ }^{26}$ y en la conjunción de capitalismo y patriarcado. ${ }^{27}$ En uno y otro caso, sistema patriarcal y colonial, se trata de caracterizar el modo de explotación capitalista como una masiva puesta a disposición de los cuerpos humanos y no-humanos.

El término elegido en el título, antrópico extiende el sentido del androcentrismo a otras figuras que la filosofía del siglo $x x$ ha utilizado con fruición y como supuesto antídoto a esta teleología humana demasiado humana. Lo posthumano tiene entonces para este trabajo el valor del fin de lo humano bajo el aspecto de la desarticulación del principio antrópico. Por principio antrópico nos referimos a un principio que por cierto excede la noción de humanismo (y por lo tanto también de su fin), ya que no solo brota en las ciencias humanas sino, sobre todo y subrepticiamente, en las así llamadas naturales, donde, como indica Fabián Ludueña en Más allá del principio antrópico, se acuña su sentido fuerte. El principio antrópico fuerte es aquel que jerarquiza lo existente en torno al privilegio de la vida y con ella de lo humano como su ejemplo más acabado. Aun cuando la vida sea un fenómeno ínfimo en el universo, el principio antrópico determina su prerrogativa como objeto dignísimo y primerísimo de estudio, búsqueda y explicación. ${ }^{28}$ Salirse de la teleología humana, y a la vez salir de la trampa del fin del hombre como simple fin del humanismo, tal como ha sido pensado y discutido al menos desde la polémica Sartre-Heidegger, esa es quizás la cuestión. Se trata de desplazar la teleología humana que pone al propio hombre como fin, y esto implica desplazar también la sombra del hombre en el concepto de vida.

Pensar más allá del principio antrópico, sin embargo, no debe conducirnos a ninguna idea de superación, no pretende repetir el gesto hegeliano donde la caída anuncia un nuevo ascenso. Si así fuera diríamos que más allá del hombre y su arte, llega bajo el signo de lo nuevo la figuración posthumana. Por el contrario, querríamos pensar esa potencia figurante como aquello que crece y está siempre allí antes y al lado de lo que ya hoy parece un estribillo repetido hasta perder su sentido: las muertes del arte y del hombre. Ahora bien, ¿qué tipo de solución o alternativa podría dar a este
${ }^{25}$ Cfr. G. Deleuze y F. GuATTARI, Mil mesetas, ed. cit., p. 183.

${ }^{26}$ Cfr. Eduardo GRÜnER, La oscuridad y las luces. Capitalismo, cultura y revolución, Buenos Aires, Edhasa, 2010.

${ }^{27}$ Cfr. Silvia Federici, Calibán y la bruja. Mujeres, cuerpo y acumulación originaria, trad. Verónica Hendel y Leopoldo Sebastián Touza, Buenos Aires, Tinta Limón, 2016 (Nueva York, 2004).

${ }^{28}$ Fabián Ludueña RomanDini, Más allá del principio antrópico. Hacia una filosofía del outside. Buenos Aires, Prometeo, 2012. 
29 M. Foucault, Las palabras y las cosas, ed. cit., p. 9.

$30 \mathrm{~K}$. Barad, Meeting the world halfway..., ed. cit.

31 Michel Foucault, La pintura de Manet, trad. Horacio Pons, Buenos Aires: Fondo de Cultura Económica, 2015 ( $\mathrm{Pa}$ rís, 2004).

32 Michel Foucault, «La pintura fotogénica» en Cuadernos Materialistas, 2, 2017, p. 81-91. callejón sin salida de las convalecencias, las muertes y los finales la postulación de una figuración posthumana? ¿Cómo estar entre y con lo no-humano sin reproducir la vieja lógica de la apropiación?

Para comenzar a esbozar esta cuestión, es necesario pensar con más detalle qué sentido tiene la idea misma de una figuración, y como podría ir más allá del principio antrópico. Es Foucault quien al operar su particular torsión al motivo nietzscheano del fin del hombre lo presenta en términos de figura: el hombre es una figura, pliegue o forma del saber, que desaparecerá cuando aparezcan nuevas formas. ${ }^{29}$ Vemos que en estos términos el hombre es figura, donde la potencia figurante podría decantar en términos humanos, pero también podríamos pensar las formas que caen a su lado, como pluralidad figurante y plástica. Estas nuevas formas, entonces, no implican la desaparición de los hombres, pero su advenimiento depende en cierto modo de una desfiguración y reconfiguración, un trabajo plástico que, de acuerdo con la lectura deleuziana de Foucault, deberá cargar al hombre de animales, de rocas, de lo inorgánico. 0 lo que es lo mismo, deberá reconfigurar inhumanamente al hombre, en tanto que esta carga se dirige especialmente a romper con aquello que el concepto de hombre obtura a la hora de pensar lo existente: su necesaria configuración jerárquica. Este trabajo de reconfiguración no es ajeno a cierto modo de pensar el arte y especialmente la imagen. Cargarse no debe entenderse solamente bajo la forma nietzscheana del camello: Ilevar consigo nuevas ataduras. Cargarse de animales y rocas no es hacer de las rocas y los animales nuevos sujetos. La carga debe ser entendida a la luz del campo semántico de la carga electromagnética, dejarse modificar por el contacto con otros cuerpos y velocidades. Dejarse arrastrar. A propósito de esta perspectiva, Karen Barad ha señalado con justeza que a menudo la deconstrucción del concepto de sujeto que denuncia en él un efecto discursivo antes que una causa del sentido, se mantiene en la superficie cultural de los efectos simbólicos y discursivos, olvidando el problema material abierto por cualquier inversión de la prerrogativa idealista que compone la metafísica del sujeto. Los cuerpos y su materia, sus componentes y compuestos, no pueden sublimarse rápidamente hacia el problema de los discursos. Es necesario pensar las relaciones y las acciones, los compuestos y sus efectos, en el nivel de la materia misma, de sus materiales y propiedades físicas. ${ }^{30}$ Como indica el propio Foucault en sus escritos sobre Manet, en el cuadro lo que hay en primer lugar es una particular relación de la tela, con su trama de hilos horizontales y verticales, y las propias líneas de la composición. ${ }^{31} 0$ también en un texto quizás no lo suficientemente visitado sobre Fromanger de 1975,32 donde Foucault reconstruye los probables orígenes de la imagen fotográfica en términos de emancipación de las imágenes, donde la vida alocada de 
las imágenes reproducidas era indisociable de su potencia material, del acceso a su manipulación en todo tipo de soportes.

Vemos que en el texto foucaultiano sobre Fromanger la imagen no señala únicamente el efecto derivado de un auténtico existente, sino un particular modo de ser en el mundo, ser entre y en relación, pero a la vez separado. Ser vital, en tanto que expresa un particular afecto y actúa a su modo y más allá de todo control, pero claramente no biológicamente vivo, no individual y no personal. ¿No podrá esta vida inorgánica e inhumana de la imagen darnos una clave para pensar un modo de ser en el mundo abandonado de toda finalidad humana? 0 en otros términos, ¿puede cierta vida inorgánica de las imágenes emanciparnos del principio antrópico? Para comprender el sentido que podría tener esta vida inorgánica, es decir, una vitalidad no antrópica y a la vez una que pueda pensarse a través de la imagen, es necesario recordar que inorgánico es en primer lugar lo que no cumple con las propiedades de lo orgánico entendido como lo que puede asimilarse a la forma viva. Una forma orgánica es aquella que es determinada por un fin al que todas sus partes tienden y en pos del cual cada una cumple su función. Lo orgánico denota la forma viva porque en el viviente -y en la vida como su principio- Io que se juega es ante todo cierta idea de reproducción y crecimiento, de continuidad armónica, persistencia y perseverancia sostenidas por el cosmos como ley organizante. La naturaleza está organizada o al menos así parece. Es esta vocación de orden la que encontró el propio Kant en la Crítica del juicio. La técnica de la naturaleza, su arte, aquello que creemos reencontrar en el juicio estético como armonía de las facultades, hace de la forma de la finalidad (quizás deberíamos decir la forma sin más) la clave de bóveda del concepto moderno de belleza. El placer generado por la contemplación de la belleza natural nace de la coincidencia entre los fines del hombre y los fines de la naturaleza. De este modo, la naturaleza orgánica y organizada no es sino a semejanza del hombre, especialmente cuando el hombre encuentra la razón de su existencia en la consecución del fin, el propio y el del cosmos.

\section{Algunas conclusiones}

El encuentro o la colaboración con los no-humanos debería abrir la posibilidad de un desvío respecto de los fines. Imitar la naturaleza, reproducir sus estructuras y arquitecturas, ampliar el horizonte del paisaje natural dispuesto para la contemplación humana y el goce en lo bello hacia mundos microscópicos y macroscópicos, ampliar el círculo de lo bello hacia estructuras y formas naturales poco atendidas, no rompe con el hechizo del paisaje. La naturaleza como paisaje sigue siendo la naturaleza expuesta para 
33 Cfr. Donna Haraway, «Symbiogenesis, sumpoiesis, and art science activism for staying with the trouble» en A. Tsing, \& et. alt., Monsters of the anthropocene, Minneapolis, University of Minnesota Press, 2017, p. 25-50.

${ }^{34}$ G. Deleuze y F. Guattari, ¿Qué es la filosofía?, ed. cit., p. 170. su uso, dispuesta como recurso. Quizás un gesto distinto al de Saraceno podamos encontrar en la relación que Deleuze y Guattari pensaron en torno a la música y los pájaros o los insectos. Si seguimos el hilo del argumento desplegado en la meseta Ilamada Del ritornelo y en algunas de las clases que Deleuze dedicó a la cuestión de música, podemos comprender que el vínculo con la naturaleza nunca se limita a reconstruir y extraer sus formas, sino entrar en el devenir que esas formas implican. Alcanzar la frecuencia del insecto, la velocidad del canto del pájaro, explorar frecuencias imposibles para les humanes pero que justamente en el umbral de la imposibilidad y solo allí abren afectos nuevos y poderosos. Una simpoiesis ${ }^{33}$ antes que una colaboración, donde el hacer-junto no admite ninguna separación individuante. El gesto quizás menos desjerarquizado de la obra de Saraceno se encuentra no tanto en la más visible explotación de las arañas, sino en la utopía aerocénica. Una salida por arriba, limpia, sublimizada, sin ningún tipo de contaminación, sin resto opaco y barroso, no puede sino ser el epítome del idealismo.

Por el contrario, y siguiendo a Adorno, intentamos aquí declinar el posthumanismo sobre un materialismo que se mezcla con los cuerpos en sus humores y aromas, en su descomposición común. Desde la perspectiva de la producción imaginaria y artística, esto implica una continuidad entre las imágenes y lo existente en general, que bloquea toda jerarquía derivada de un uso extractivo y dispuesto para los fines humanos de cualquier producción sensible no-humana. Si la imagen artística implica, como dicen Deleuze y Guattari, afectos y perceptos; es decir, devenires no humanos del hombre y paisajes no humanos de la naturaleza ${ }^{34}$, entonces lo que debemos pensar como figuración posthumana se dirige a la interrupción de la finalidad humana de toda producción imaginaria. Así las cosas, la vida inorgánica de las imágenes que referíamos un poco antes, adquiere una importancia insoslayable cuando se la proyecta sobre el problema de la producción imaginaria de los agentes no humanos.

Interrumpir la lógica antrópica y teleológica de la producción de imágenes y con ellas la del arte en general podría sin embargo leerse en términos de un nuevo avatar del carácter de pasado del arte. No repetiremos aquí el sentido hegeliano de este término y sus relecturas contemporáneas, pero sí nos gustaría abrir la cuestión que necesariamente se deriva del análisis anterior. ¿Cómo puede entenderse un más allá del arte por fuera de la lógica de la finalidad? Podríamos contestar a esta pregunta dantianamente, a través de la afirmación de una poshistoria pluralista, en la que el sentido ha sido arrancado de la finalidad histórica porque su lógica progresiva y emancipatoria ha perdido inteligibilidad. Esta vía, sin embargo, se da de bruces con todo descentramiento de lo humano, en tanto que el sentido 
del arte se corre hacia la deriva de su interpretación necesariamente humana. Es decir, perdido todo horizonte teleológico que sostenga la evolución del arte, su sentido se torna todavía más humano. Si los materiales y su evolución permitían fundamentar el criterio de validez de lo que todavía en las vanguardias se pensaba bajo la lógica de un progreso del arte, hoy se abandona todo privilegio de la materialidad (principio de indiscernibilidad dantiano) y entonces es solo la subjetividad hiperbolizada del artista o el curador y en última instancia del crítico, el fundamento último de la producción artística. La posthistoria es así un neorromanticismo.

La imagen debe dejarnos entrever qué tipo de operación figurante, qué nueva figura debe advenir cuando pensamos una desjerarquización radical de los agentes productores de imágenes y sensaciones, es decir aquello de lo que deberá cargarse el arte para modificar su figura. Es así que la vida inorgánica de la imagen, tal como la hemos caracterizado, puede abrir una salida no idealista al fin de la deriva ascética del arte, tal como la caracterizaba Foucault. Y la imagen, ese ser intermedial que permite la comunicación sensible, es decir el ser en común sensible, con su potencia influenciante y su poder tergirversante, es la que debe generar las nuevas formas para el arte y para una nueva figura del hombre. La vitalidad de la imagen es entonces aquella de la agencialidad descontrolada, falsificante, bastarda. Es su propia falta de fin y de origen lo que puede abrir la reflexión sobre su poder emancipatorio, desligado ya de toda teleología histórica. Emancipar la sensación tanto del sentir humano como de los fines humanos del arte. Erigir modos de ser en el mundo diversos que habiliten un pensamiento multiversal. Una vida inorgánica de las imágenes, que crecen y se reproducen como cristales, como alternativa figurante para ese más allá del hombre anunciado por Foucault.

Guadalupe Lucero

Universidad de Buenos Aires. CONICET

guadalupe.lucero@gmail.com 
SARACENO Y LA ARAÑA: LA FIgURACIÓn POSTHUMANA, ENTRE REAPROPIACIONES Y DERIVAS NO ANTRÓPICAS.

En este trabajo nos proponemos realizar una lectura crítica de la obra reciente del artista argentino Tomás Saraceno, desde la perspectiva del materialismo posthumano. Contra gran parte de la crítica que ha señalado en esta obra un ejemplo de colaboración interespecie y una suerte de utopía que habilita nuevas formas de vida para un mundo por venir, nuestro objetivo es señalar cómo se reproduce en este ejemplo una lógica que hace de todo lo existente una cantera disponible para la extracción de recursos (materiales y simbólicos) teleológicamente destinados al existente humano. Acuñamos el término figuración posthumana para pensar alternativas no antrópicas que habiliten modos de ser imaginarios más allá de toda prerrogativa humana.

Palabras clave: Saraceno, figuración posthumana, posthumanismo, materialismo

Saraceno and the spider: Posthuman figuration, Between Reappropriations and non anthropic DRIFTS

In this paper we propose a critical approach to some recent works of the argentine artist Tomas Saraceno, from the perspective of the posthuman materialism. Many critics of this work have pointed out in it an example of interspecies collaboration and the utopic attempt of creating new ways of life for a new world to come. Against this perspective, we aim to show how this example reproduces the capitalistic logic that turns all existence into available resources (both material and symbolic), and also teleologically destined for the human existence. Our proposal of a post-human figuration will let us think of non-anthropic alternatives that enable imaginary ways of being beyond any human prerogative.

Keywords: Saraceno, posthuman figuration, posthuman, materialism 
Aquest article ha estat publicat originalment a Matèria. Revista internacional d'Art (ISSN en línia: 2385-3387)

Este artículo ha sido publicado originalmente en Matèria. Revista internacional d'Art (ISSN en línea: 2385-3387)

This article was originally published in Matèria. Revista internacional d'Art (Online IS S N : 2385-3387)

\section{MATÈRIA}

Revista internacional d'Art

Els autors conserven els drets d'autoria i atorguen a la revista el dret de primera publicació de l'obra.

Els textos es difondran amb la llicència de Reconeixement-NoComercialSenseObraDerivada de Creative Commons, la qual permet compartir I'obra amb tercers, sempre que en reconeguin I'autoria, la publicació inicial en aquesta revista i les condicions de la llicència: https://creativecommons. org/licenses/by-nc-nd/4.0/deed.ca

Los autores conservan los derechos de autoría y otorgan a la revista el derecho de primera publicación de la obra.

Los textos se difundirán con la licencia de Atribución-NoComercial-SinDerivadas de Creative Commons que permite compartir la obra con terceros, siempre que éstos reconozcan su autoría, su publicación inicial en esta revista y las condiciones de la licencia: https://creativecommons.org/licenses/ by-nc-nd/4.0/deed.es

The authors retain copyright and grant the journal the right of first publication.

The texts will be published under a Creative Commons Attribution-NonCommercial-NoDerivatives License that allows others to share the work, provided they include an acknowledgement of the work's authorship, its initial publication in this journal and the terms of the license: https://creativecommons.org/licenses/by-nc-nd/4.0/deed.en

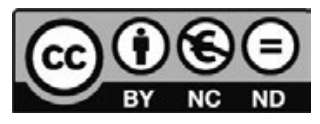

